\title{
Correction to: Invasive Species \\ in Forests and Rangelands of the \\ United States
}

Therese M. Poland, Toral Patel-Weynand,

Deborah M. Finch, Chelcy Ford Miniat,

Deborah C. Hayes, and Vanessa M. Lopez

\section{Correction to:}

T. M. Poland et al. (eds.), Invasive Species in Forests and Rangelands of the United States, https://doi.org/10.1007/978-3-030-45367-1

The original version of this book was revised as the editor has provided belated corrections for Page xiv, Page 2, Page 19, Page 32, Page 141, Page 159, Page 191, Page 192, Page 194, Page 213, Page 325, Page 343, Page 366, Page 368, and Page 423.

Editor has also requested to add "Disclaimer Text" at the end of each chapter. The book corrections has now been incorporated and approved by the Editor. 